\title{
POLARIS: ESA's airborne ice sounding radar front-end design, performance assessment and first results
}

\author{
Hernández, Carlos Cilla; Krozer, Viktor; Vidkjær, Jens; Dall, Jørgen
}

Published in:

IEEE MTT-S International Microwave Symposium Digest, 2009. MTT '09

Link to article, DOI:

10.1109/MWSYM.2009.5165716

Publication date:

2009

Document Version

Publisher's PDF, also known as Version of record

Link back to DTU Orbit

Citation (APA):

Hernández, C. C., Krozer, V., Vidkjær, J., \& Dall, J. (2009). POLARIS: ESA's airborne ice sounding radar frontend design, performance assessment and first results. In IEEE MTT-S International Microwave Symposium Digest, 2009. MTT '09 (pp. 393-396). IEEE. https://doi.org/10.1109/MWSYM.2009.5165716

\section{General rights}

Copyright and moral rights for the publications made accessible in the public portal are retained by the authors and/or other copyright owners and it is a condition of accessing publications that users recognise and abide by the legal requirements associated with these rights.

- Users may download and print one copy of any publication from the public portal for the purpose of private study or research.

- You may not further distribute the material or use it for any profit-making activity or commercial gain

- You may freely distribute the URL identifying the publication in the public portal 


\title{
POLARIS: ESA's Airborne Ice Sounding Radar Front-End Design, Performance Assessment and First Results
}

\author{
Carlos Cilla Hernández, Viktor Krozer, Jens Vidkjær and Jørgen Dall \\ Technical University of Denmark, Kgs. Lyngby, Orsteds Plads 348, 2800 Denmark
}

\begin{abstract}
This paper addresses the design, implementation and experimental performance assessment of the RF front-end of an airborne $P$-band ice sounding radar. The ice sounder design comprises commercial-of-the-shelf modules and newly purposebuilt components at a centre frequency of $435 \mathrm{MHz}$ with $20 \%$ relative bandwidth. The transmitter uses two amplifiers combined in parallel to generate more than $>128 \mathrm{~W}$ peak power, with system $>60 \%$ PAE and $47 \mathrm{~dB}$ in-band to out-of-band signal ratio. The four channel receiver features digitally controlled variable gain to achieve more than $100 \mathrm{~dB}$ dynamic range, $2.4 \mathrm{~dB}$ noise figure, $160 \mathrm{~ns}$ receiver recovery time and $-46 \mathrm{dBc} 3^{\text {rd }}$ order IMD products. The system comprises also, a digital front-end, a digital signal generator, a microstrip antenna array and a control unit.

All the subsystems were integrated, certified and functionally tested, and in May 2008 a successful proof-of-concept campaign was organized in Greenland. The system detected the bedrock under $3 \mathrm{~km}$ of ice, and internal layers were mapped up to $1.3 \mathrm{~km}$.

Index Terms - Airborne radar, microwave power amplifiers, microwave switches, power dividers, radar transmitters, radar receivers
\end{abstract}

\section{INTRODUCTION}

The European Space Agency (ESA) has proposed a spaceborne ice sounding radar as a candidate for the next Earth Explorer missions [1]. A mapping of the ice with its internal ice sheets structure would help to understand the ice past history and predict the future evolution and the impact of the climate changes in the ice poles. However, the scattering properties of the ice at P-band are not sufficiently well known. In order to close this knowledge gap, an airborne P-band ice sounding radar demonstrator has been initiated, called hereafter Polaris. Within two years, DTU has designed and implemented the full instrument including aircraft installation, a proof-of-concept campaign and data processing.

Key parameters of the instrument are listed in Table I and additional specifications and requirements are found in [2].

TABLE I

P-SOUNDER SPECIFICATIONS

\begin{tabular}{|c|c|}
\hline Centre frequency & $435 \mathrm{MHz}$ \\
\hline Bandwidth (goal) & $85 \mathrm{MHz}$ \\
\hline Polarization & Quad \\
\hline Maximum pulse length & $50 \mu \mathrm{s}$ \\
\hline Peak power & $100 \mathrm{~W}$ \\
\hline Maximum PRF & $20 \mathrm{kHz}$ \\
\hline
\end{tabular}

The capabilities of the system include a fairly high relative bandwidth (20\%), an accurate internal calibration, thermal stabilization, a large dynamic range, pulse-to-pulse coherence, a high sensitivity sufficient to detect the bedrock through $4 \mathrm{~km}$ of ice and sufficient surface clutter suppression. The former was implemented using a novel technique based on a multiaperture antenna.

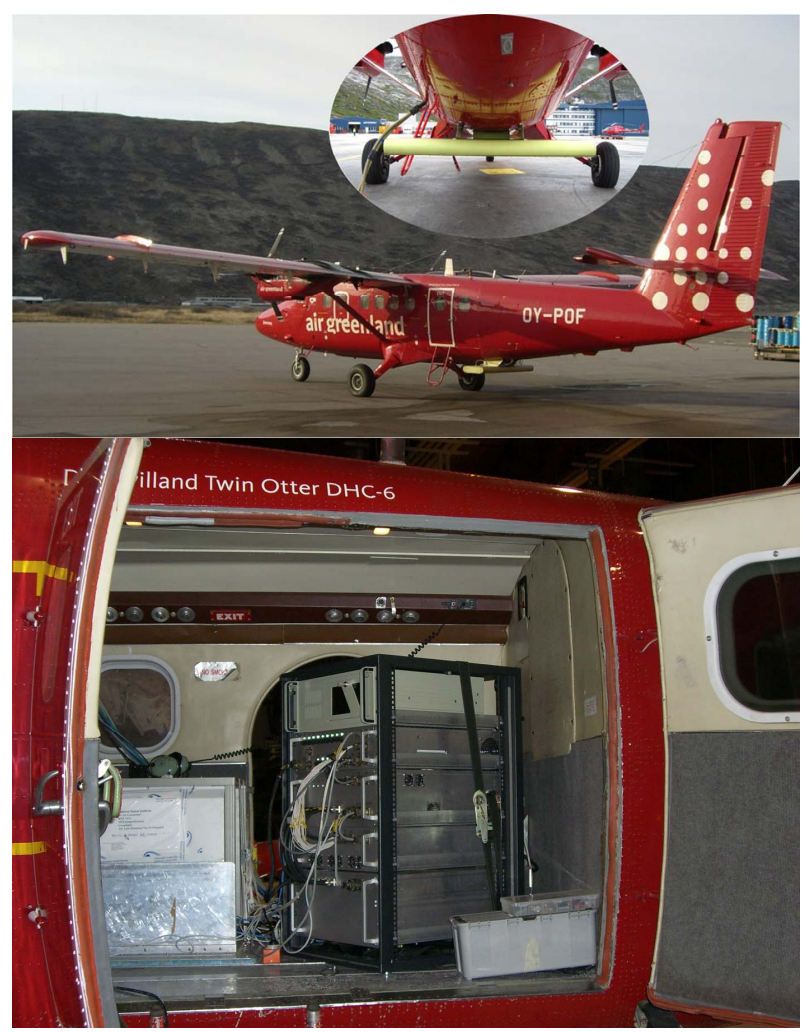

Fig. 1. Polaris system installed in the Twin Otter aircraft.

The system comprises an RF front-end, a digital front-end, a digital signal generator, a control unit, a storage module, a navigation module and a newly developed wideband probefed dual-linear polarization wideband microstrip patch antenna. All the subsystems have been successfully developed and integrated, and they were presented in previous publications [3],[4],[5].

The radar was installed, certified and functionally tested on a Twin Otter aircraft (Fig. 1) in March 2008, and the proof-ofconcept campaign took place in May 2008 in Greenland. 
This paper presents the RF Front-End design and performance assessment. At the end, a few results from the May 2008 campaign are presented.

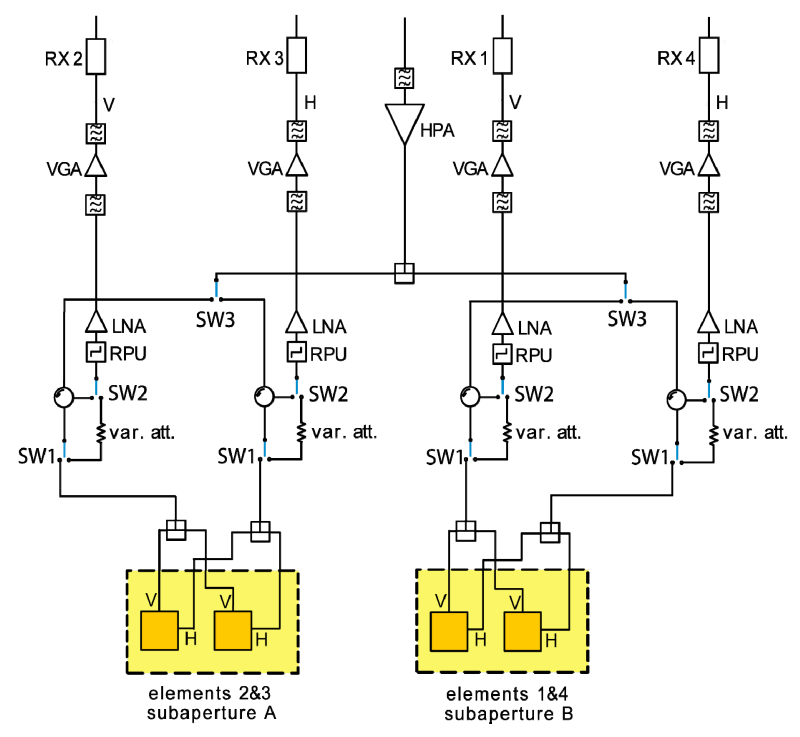

Fig. 2. RF Front-End Architecture.

\section{SYSTEM IMPLEMENTATION}

The RF Front-End architecture (Fig. 2) comprises a classical design with a central transmitter and four receiver channels mounted inside the aircraft plus a four patches dual-polarized antenna mounted underneath the aircraft body. This configuration has been selected over a more advanced distributed system with transmit and receive modules mounted directly behind the antenna elements mainly because of aircraft certification restrictions. The Polaris design is based on in-house module developments for the antenna, power amplifier, the high power nanosecond switch, a variable gain amplifier and power dividers and combiners, while all other components are commercial-off-the-shelf (COTS).

The transmitter is composed of two high power highefficiency LDMOS amplifiers combined in parallel (HPA), a high power SPDT PIN switch (SW3), a circulator, a slow high power relay for calibration and in-phase and out-of-phase high power splitters. A system analysis based on ice scattering models [6] showed that the selected configuration with a transmitter peak power of $100 \mathrm{~W}$ would be sufficient to detect the bedrock down to $4 \mathrm{~km}$.

The receiver comprises a pin diode limiter (RPU), a lownoise amplifier, band pass filters and a variable gain amplifier that provides sufficient gain to drive optimally the A/D converters in the digital acquisition unit. The variable gain receiver is used to provide a high dynamic range exceeding $100 \mathrm{~dB}$, allowing a shallow/deep sounding approach. Alternating the receiver gain in a pulse-to-pulse basis makes it possible to map both the near-surface and near-bottom ice windows simultaneously.

Based on DTU's experience with the airborne EMISAR system [7], the internal calibration is implemented by toggling the switches SW1 and SW2 in order to loop the generated pulses around the system.

Below, the three in-house purpose-built modules used in the system are briefly outlined: in-phase and out-of-phase high power dividers, a high power SPDT PIN switch and a solid state high efficiency power amplifier. Further details about these newly developed modules can be found in [5].

We have developed lumped element Wilkinson type inphase and out-of-phase power dividers. Such realizations have been presented earlier [8],[9], but did no have the RF power handling capabilities. Both designs present the required $20 \%$ bandwidth with return loss better than $15 \mathrm{~dB}$ and $100 \mathrm{~W}$ power handling. The in-phase design presents amplitude difference of $0.1 \mathrm{~dB}$, insertion loss of $0.2 \mathrm{~dB}$ and phase balance $<1^{0}$, while the out-of-phase performs with $0.23 \mathrm{~dB}$ amplitude unbalance, $0.5 \mathrm{~dB}$ insertion loss and phase balance $<2^{0}$. Layout details have been presented earlier [4],[5].

A high power PIN diode switch controlled by a TTL signal, and with $90 \mathrm{~W}$ power handling capabilities has been developed [10]. The measured return loss at the three ports is better than $15 \mathrm{~dB}$, the insertion loss is lower than $0.6 \mathrm{~dB}$ and the isolation is better than $42.5 \mathrm{~dB}$ across the full band. The turn-on time is $500 \mathrm{~ns}$ and the turn-off time $300 \mathrm{~ns}$, without observing high voltage switching transients.

We have developed a 70W CW LDMOS power amplifier (Fig. 3) with $60 \%$ PAE, $0.1 \mathrm{~dB} 395-475 \mathrm{MHz}$ bandwidth and $38.9 \mathrm{~dB}$ gain. The design operates in class $\mathrm{E}$ and it comprises a driver and a power stage. Measured parameters are in excellent agreement with simulated results using the Freescale LDMOS model.

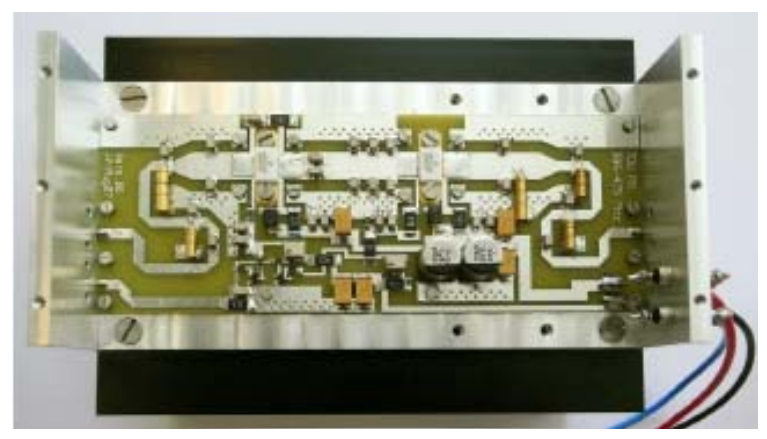

Fig. 3. Purpose-build Power Amplifier module.

\section{SYSTEM PERFORMANCE}

\section{A. Transmitter}

The transmitter contains two in-house purpose-build $70 \mathrm{~W}$ high power amplifiers combined in parallel by high power 
lumped element Wilkinson combiners. The bias networks of both amplifiers were carefully adjusted to achieve identical performance and to avoid imbalances. A maximum combined power of $128.8 \mathrm{~W} \mathrm{CW}$ was measured, but due to power handling limitation of the power combiners and in order to guarantee a high reliability, it was decided to operate both power amplifiers in back-off during flight. Therefore, during the proof-of-concept campaign, the transmitter was generating $102 \mathrm{~W}$ peak power at $475 \mathrm{MHz}$ with a total PAE of $44 \%$.

Comparing the single amplifier performance with the combined one, the gain flatness is degraded from $0.1 \mathrm{~dB}$ to $1 \mathrm{~dB}$ and the efficiency is reduced from $60 \%$ to $40 \%$. This is a direct consequence of driving the power amplifiers in backoff, and also due to the limited bandwidth of the power combiners. The former imply that the power amplifiers are not loaded with $50 \mathrm{Ohms}$ at the higher order harmonics, and this can have a significant impact in the performance [11].

The transmitter was tested with an $85 \mathrm{MHz}$ bandwidth pulsed signal generated by the Digital Signal Generator (DSG), and the measured in-band to out-of-band signal ratio was larger than $47.6 \mathrm{~dB}$. The measured noise generated by the transmitter during reception was found to be under the noise floor of the spectrum analyzer $(-90.5 \mathrm{dBm})$. This is important since the transmitter and receiver are separated only by a circulator.

\section{B. Receiver}

The receiver chain S-parameter measurements were performed between the cables connected to the antenna ports and the receiver output. The input power level used during the measurements was adjusted to have always $-20 \mathrm{dBm}$ at the receiver output. Fig. 4 shows the transducer gain of one of the channels for different gain settings. An in-band ripple of around $1 \mathrm{~dB}$ is observed. The return loss at the input is better than $12.8 \mathrm{~dB}$ across the bandwidth. The S-parameters where measured for the four receiving channels, observing always a good agreement among each other. This is important in order to implement the surface clutter suppression algorithms. The noise figure of the receiver was initially around $\mathrm{NF}=0.5 \mathrm{~dB}$, but subsequently deteriorated by the limiter, the circulator and other passives placed in front of the LNA. However it is still better than $2.4 \mathrm{~dB}$ for the high gain settings, whereas it is notably degraded when using low gain settings.

The PIN diode limiter placed in front of the LNA is needed to protect the receiver during the transmission of high power pulses, but it also introduces a recovery time. This is defined as the time until the receiver recovers its normal sensitivity after an overvoltage at the input of the limiter. Figure 5 shows the recovery time measured with an oscilloscope. The channel on the foreground is the result of combining a $-45 \mathrm{dBm} \mathrm{CW}$ signal and a pulsed signal that activates the limiter, and the channel in the background is the output of the receiver. It is possible to observe that the evolution of the receiver output is distorted during 800ns, but the time that the receiver is completely blind is only around 160ns.

Measurements of the receiver third order IMD products were performed placing two combined tones at 435 and 436 $\mathrm{MHz}$ at the receiver input, and adjusting the input power to have $0 \mathrm{dBm}$ at the receiver output. The third order IMD products are around $-52 \mathrm{~dB}$ in the low gain range, and $-46 \mathrm{~dB}$ in the high gain range.

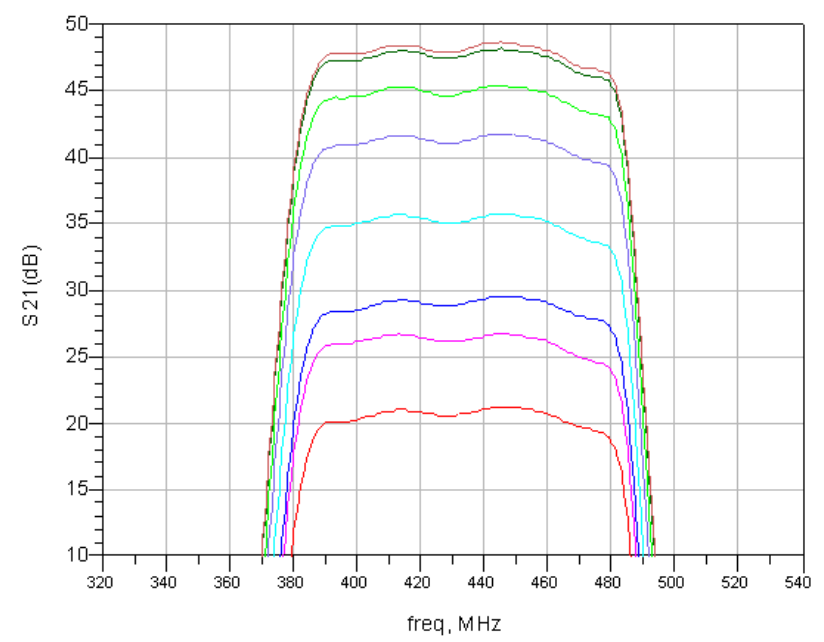

Fig. 4. Receiver transducer gain for different gain settings.

The transmitter and receiver were tested together looping the generated high power pulses around the calibration path $(\mathrm{PRF}=10 \mathrm{KHz}$, Pulse Length $=10 \mu \mathrm{s}, \mathrm{BW}=85 \mathrm{MHz}$ and Duty Cycle $=10 \%$ ). The spectrum shown in Fig. 6 was measured at the output of the receiver depicting a $1.5 \mathrm{~dB}$ ripple in the system response across the full bandwidth. This ripple was carefully compensated using digital pre-distortion techniques.

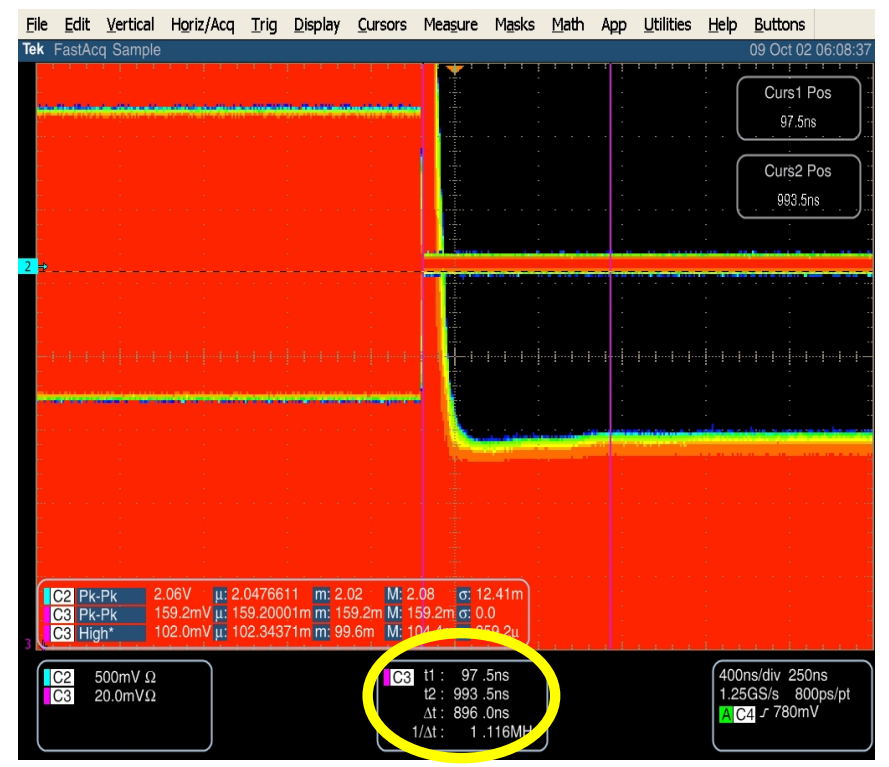

Fig. 5. Receiver measured recovery time. . 


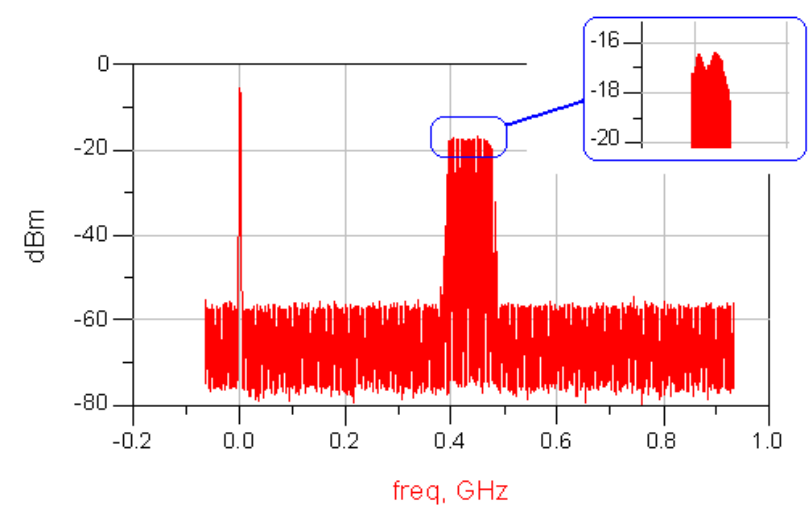

Fig. 6. Spectrum at the output of the receiver when high power pulses are looped around the system during a system calibration.

\section{CAMPAIGN RESULTS}

The proof-of-concept campaign took place in Greenland in May 2008. Fig. 7 shows the bedrock detected through almost $3 \mathrm{~km}$ of ice in the dry snow zone in Greenland. According to ice models [6], $2.5 \mathrm{~km}$ of warm ice in Greenland are comparable to $4 \mathrm{~km}$ of cold ice in Antarctica. Internal ice layers were also detected with a resolution of several meters, but are subject of another paper.

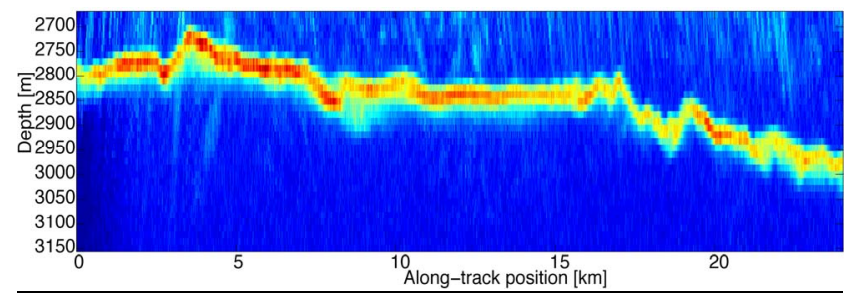

Fig. 7. Bedrock in Greenland detected through $3 \mathrm{~km}$ of ice.

\section{CONCLUSION}

We have presented the RF Front-End design and performance assessment of and airborne P-band ice sounding radar. State-of-the-art modules have been developed for the system: compact high power power dividers with $100 \mathrm{CW}$ power handling, a high power SPDT PIN switch handling 90W CW and nanosecond switching times, and a $70 \mathrm{~W} \mathrm{CW}$ high efficiency LDMOS power amplifier with $>60 \%$ PAE. The transmitter generates more than $128 \mathrm{~W}$ peak power, with $60 \%$ PAE and $47 \mathrm{~dB}$ band to out of band signal ratio. The receiver performance features more than $100 \mathrm{~dB}$ dynamic range, $2.4 \mathrm{~dB}$ noise figure, $160 \mathrm{~ns}$ receiver recovery time and $-46 \mathrm{dBc} 3 \mathrm{rd}$ order IMD products in the worse case.
In May 2008, a successful proof-of-concept campaign was organized in Greenland, detecting internal ice layers and the bedrock under $3 \mathrm{~km}$ of ice. New activities related to the project are ongoing: a new microstrip antenna with eight dual polarized patches is being designed, the transmitted peak power will be increased with a new power amplifier operating in the $200 \mathrm{~W}$ range with $>60 \%$ PAE and new data acquisition campaigns are foreseen in the near future.

\section{ACKNOWLEDGEMENT}

The partial financial support by the European Space Agency under contract no._19307/05/NL/JA is acknowledged by the authors.

\section{REFERENCES}

[1] C.-C. Lin, F. Hélière, P. Bensi, A. Thompson, M. Aguirre, C.Buck, M. Ludwig, M. Süss, N. Le Gallou, M. Aloisio, C.Mangenot, K. van't Klooster, P. Rinous, J.S. Prowald, B. Rommen, N. Floury, A. Wielders, "ESA's SAR technology and future mission concept developments beyond Sentinel-1", Proc. of EUSAR 2008, Vol. 2, pp. 123-126 Friedrichshafen, June 2008.

[2] J. Dall, N. Skou, A. Kusk, S. S. Kristensen, V. Krozer, "Design of an airborne P-band ice sounding radar", Proc. Workshop on Advanced RF Sensors for Earth Observation 2006, Noordwijk, The Netherlands, Dec. 2006.

[3] J. Dall, S.S Kristensen, V. Krozer, C.C. Hernández, J.Vidkjær, A. Kusk, J. Balling, N. Skou, S.S. Søbjærg, E.L. Christensen, "Implementation of an airborne P-band ice sounding radar", Proc.EUSAR 2008, Vol. 2, pp. 103-106 Friedrichshafen, June 2008.

[4] V. Krozer, C. Cilla, J. Vidkjær and J. Dall, "Development of an Airborne Ice Sounding Radar Front-End", European Microwave Week, October 2007.

[5] C. Cilla, V. Krozer, J. Vidkjær and J.Dall, "Design and Performance Assessment of an Airborne Ice Sounding Radar Front-End", Proc. ESA Microwaves Workshop 2008, Noordwijk, The Netherlands, May. 2008.

[6] "Annex 2 to P-band Ice Sounding Radar Demonstrator Development, A simplified scattering model", ESTEC TECETP/2004.31, version 2, November 2004.

[7] E. L. Christensen, N. Skou, J. Dall, K. Woelders, J. H. Jorgensen, J. Granholm, and S. N. Madsen, EMISAR: An Absolutely Calibrated Polarimetric L- and C-band SAR, IEEE Trans. Geoscience and Remote Sensing, vol. 36, no. 6, pp. 1852--1865, Nov. 1998.

[8] M. Chongcheawchamnan, N. Siripon, and I.D. Robertson, "Design and performance of improved lumped-distributed Wilkinson divider topology," Electronics Letters, vol. 37, no. 8, pp. $501-503,2001$.

[9] H.S. Nagi, "Miniature lumped element 180/spl deg/ Wilkinson divider," 2003 IEEE MTT-S Microwave Symposium Digest, vol. 1, pp. 55-58 vol.1, 2003.

[10] G. Hiller, "Design with PIN diodes", MA-COM Application Note.

[11] Steven C. Cripps, Advanced Techniques in RF Power Amplifier Design, Artech House Publishers, 2002. 